\title{
Mechanical and electrical characterisation of a phase transformation in thermal barrier coatings
}

\author{
A. Shinmi, X. Zhao, P. Xiao* \\ Material Science Centre, School of Materials, University of Manchester, Grosvenor Street, Manchester M1 7HS, UK
}

\section{A R T I C L E I N F O}

Article history:

Received 30 April 2010

Accepted in revised form 12 October 2010

Available online 19 October 2010

\section{Keywords:}

Thermal barrier coating

Phase transformation

Sintering

Impedance spectroscopy

Mechanical properties

\begin{abstract}
A B S T R A C T
The electrical and mechanical properties of atmospheric plasma sprayed (APS) yttria stablised zirconia (YSZ) thermal barrier coatings (TBCs) were determined using impedance spectroscopy and an indentation technique, respectively. Upon thermal exposure, sintering and phase transformation occurs in the YSZ TBCs, leading to changes in both the mechanical and electrical properties of the TBCs. After the thermal treatment, the formation of the monoclinic phase in the YSZ TBCs reduced the density of the TBCs and thus affected both the mechanical properties and conductivity of the TBCs. In this study, a relationship between the electrical and mechanical properties of APS TBCs has been established, allowing us to evaluate the properties of TBCs nondestructively with the use of impedance spectroscopy.
\end{abstract}

(c) 2010 Elsevier B.V. All rights reserved.

\section{Introduction}

Thermal barrier coatings (TBCs) have been applied to the hot section parts in industrial gas turbines and aero engines to increase the turbine inlet temperature, reduce the temperature of the metal substrate used in the hot section and prolong the life of these components [1-5]. These components are normally used in a high temperature environment for a long time. Therefore, TBCs must be capable of withstanding a high temperature environment during gas turbine operation. TBCs are mainly deposited using an atmospheric plasma spray (APS) or electron beam physical vapour deposition (EBPVD) technique. A TBC system normally consists of three parts; i) ceramic top coating, usually $\mathrm{Y}_{2} \mathrm{O}_{3}$ partially stabilised $\mathrm{ZrO}_{2}$ (YSZ), which provides thermal insulation due to its low thermal conductivity, ii) thermally grown oxide (TGO), mainly alumina, which is produced from oxidation of the underneath metallic bond coat, iii) bond coat ( $\mathrm{MCrAlY}, \mathrm{M}=\mathrm{Ni}$ and/or $\mathrm{Co}$ ) which promotes bonding with the top coat YSZ, and protects the underneath metallic substrate by forming a continuous and adherent TGO (e.g. alumina) layer, as described in ii), due to oxidation. It is well-known that the YSZ top coat in TBCs mainly consists of metastable tetragonal $\left(t^{\prime}\right)$ phase produced from rapid solidification during the plasma spray process [6]. During heat treatment a phase transformation occurs in the $t^{\prime}$ phase YSZ, with slow diffusion of excess $\mathrm{Y}_{2} \mathrm{O}_{3}$ from the YSZ to give equilibrium phases predicted by the $\mathrm{Y}_{2} \mathrm{O}_{3}-\mathrm{ZrO}_{2}$ phase diagram [7]. For

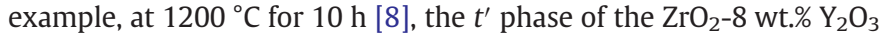

\footnotetext{
* Corresponding author. Tel.: + 44161 3065941; fax: +44 1613063586 E-mail address: ping.xiao@manchester.ac.uk (P. Xiao).
}

system transforms to the cubic (c) phase having $14 \mathrm{wt} . \% \mathrm{Y}_{2} \mathrm{O}_{3}$ and tetragonal $(t)$ phase having $4 \mathrm{wt} . \% \mathrm{Y}_{2} \mathrm{O}_{3}$, then the $t$ phase transforms to the monoclinic $(m)$ phase upon cooling. Although it is expected from the phase diagram that the $m$ phase should be formed when YSZ is cooled from higher than $1400{ }^{\circ} \mathrm{C}$ to room temperature [9], it has been reported that the $m$ phase is generated after treatment of YSZ at $1250{ }^{\circ} \mathrm{C}$ for more than $1000 \mathrm{~h}$ [10]. $1400{ }^{\circ} \mathrm{C}$ is higher than the temperature at which TBCs are used in gas turbines [11], $1250{ }^{\circ} \mathrm{C}$ for $1000 \mathrm{~h}$ is a normal turbine condition [12]. Thus the $m$ phase could form in TBCs during service. However, the $t$ to $m$ transformation in TBCs is undesirable since it leads to a volume expansion (4-5\%), which reduces the fracture toughness of the TBC, and could lead to the failure of the TBC. It has been reported that APS TBC of $\mathrm{ZrO}_{2}-8 \mathrm{~mol} \%$ $\mathrm{CeO}_{2}$ with 28 vol.\% $m$ phase in the as-sprayed coating has an obviously shorter life than other zirconia TBCs with less than $5 \mathrm{vol} . \% \mathrm{~m}$ phase in thermal cycling tests [13]. Meanwhile, it is equally important to examine the effect of the $m$ phase formation on the mechanical properties of the TBC, which is another key factor affecting the performance of TBCs in service. Therefore, it is desirable to detect the formation of the $m$ phase in TBCs non-destructively and relate it to the mechanical properties of the TBC.

A few non-destructive evaluation techniques have been used to detect the damage or stress level in TBCs [14-16]. For example, acoustic emission has been used to detect cracks in TBCs [14], where pulses of the elastic strain energy are released spontaneously during deformation. Infrared thermography has been used to examine the delamination of TBCs [15]. In this case, a pulse of heat is applied from one side of a sample and then the temperature distribution of the opposite side, which is dependent of the homogeneity of the specimen, is measured. Piezospectroscopy has been developed 
to measure stress levels and failure in TBCs non-destructively by analysis of the shape of luminescence spectra [16]. Although these techniques are useful to detect cracks, none of these techniques are suitable to examine the phase transformation in TBCs.

Impedance spectroscopy (IS) is a powerful technique to detect the microstructure and phase transformation of not only YSZ prepared by powder processing [17-19] but also YSZ TBCs [20] since IS usually demonstrates three well-defined electrical responses from YSZ $[20,21]$, which relates to the grains $(g)$, grain boundaries $(g b)$, and electrode $(e)$. The conductivity of $g\left(\sigma_{g}\right)$ is insensitive to grain size in a dense material [17] whereas it has a liner relationship with density for porous materials [18]. In addition, the conductivity of $g b\left(\sigma_{g b}\right)$ is sensitive to a change in density. An increase in conductivity of TBCs after high temperature sintering has been reported [10]. Also a variation in Young's modulus due to sintering after a thermal treatment at $1400{ }^{\circ} \mathrm{C}$ for $20 \mathrm{~h}$ has been reported [22]. At high temperature, various changes in YSZ TBC occur, which include changes in phase compositions, a grain size increase, segregation at $g b$, disappearance and generation of cracks, and TBC densification [18,23]. Therefore, it is anticipated that there should be a relationship between electrical and mechanical properties of TBC relating to these changes due to high temperature treatments. Although there have been a few studies of the degradation of TBCs based on IS $[24,25]$ or mechanical properties [22,26], and a study on the relationship between electrical and mechanical properties of TBCs [10], there has been no systematic study, to our knowledge, on how the $m$ phase formation in TBCs affects the electrical and mechanical properties of the TBC.

In this study, IS, X-ray diffraction (XRD), an indentation technique, and scanning electron microscopy (SEM) were used to characterise APS TBCs before and after thermal treatments. The effect of the thermal treatment on the microstructure, phase composition, IS, and mechanical properties have been examined. Then a relationship between the electrical and mechanical properties of TBCs has been established. Moreover how the formation of the $m$ phase influences these properties is discussed.

\section{Experimental procedure}

As-sprayed YSZ $\left(\mathrm{ZrO}_{2}-8 \mathrm{wt} . \% \mathrm{Y}_{2} \mathrm{O}_{3}\right)$ TBCs of $\sim 1 \mathrm{~mm}$ thickness were prepared on a mild steel substrate using APS (Sermatech, Derby, UK). The size of spray powders is $20-100 \mu \mathrm{m}$ and the spray condition is the standard condition in Sermatech. The TBC was removed from the substrate by immersing the TBC in a $\mathrm{HCl}$ solution at $298 \mathrm{~K}$ for $24 \mathrm{~h}$ to obtain a free standing TBC, the surfaces of both sides of the samples were polished using $\mathrm{SiC}$ paper to remove contamination on the surface before heat treatment. The thickness of the free standing coatings is around $0.8 \mathrm{~mm}$ after a polishing. These coatings were sectioned with a diamond wheel saw to produce specimens of dimensions around $25 \mathrm{~mm}^{2}$. In order to accelerate the formation of $m$ phase, the TBCs were sintered at $1400{ }^{\circ} \mathrm{C}$ in this study. The coating was heat treated at $1400{ }^{\circ} \mathrm{C}$ for up to $300 \mathrm{~h}$ with heating and cooling rates of $3 \mathrm{~K} \mathrm{~min}^{-1}$.

Before impedance measurements, silver paste was painted on both sides of the TBC sample followed by annealing at $690{ }^{\circ} \mathrm{C}$ for $30 \mathrm{~min}$ to remove the organic component in the silver paste and promote adhesion of the $\mathrm{Ag}$ paste to the TBC. Impedance measurements were carried out at $400{ }^{\circ} \mathrm{C}$ using a Solartron SI $1255 \mathrm{HF}$ frequency response analyser coupled with a Solartron 1296 dielectric interface controlled by a computer. Spectral analysis (fitting) was performed using Zview impedance analysis software (Scribner Associates Inc., Southern Pines, NC) to obtain the electrical properties of the sample. For impedance measurements, an AC (alternating current) amplitude of $100 \mathrm{mV}$ was applied to the sample and the AC frequency was in the range of $0.1 \mathrm{~Hz}$ to $10^{7} \mathrm{~Hz}$. Six data points were measured in every decade of impedance measurements.
The mechanical properties of the sample, local Young's modulus and hardness, was obtained using a microindenter (CSM Instruments, Switzerland) with a Vickers tip. These properties were obtained from polished surfaces of TBC cross sections using a standard metallurgical procedure with up to a $0.06 \mu \mathrm{m}$ OPS paste finish. The measurements were made at a fully-controlled room temperature $(298 \mathrm{~K} \pm 1 \mathrm{~K})$ in ambient air. Indentation was performed using a constant loading rate of $0.05 \mathrm{~N} / \mathrm{s}$ with a holding time of $10 \mathrm{~s}$, and at least 20 indentations were made per sample. The interval between indentations was more than $100 \mu \mathrm{m}$, which is much larger than the size of indenter, to avoid the influence of the next indentation. The Poisson's ratio of YSZ was taken as 0.3 [27] and the maximum load of the indenter was $1.5 \mathrm{~N}$. In order to obtain the mechanical properties of TBCs from the result of indentation tests, the method suggested by Oliver and Pharr [28] was adopted.

The phases of TBC samples were identified using X-ray diffraction (XRD) with Cu- $\mathrm{K}_{\alpha}$ radiation at $10 \mathrm{~mA}$ and $10 \mathrm{kV}$ (Philips, PW1830). Step scans of $0.05^{\circ}$ over the $5^{\circ} 2 \theta$ to $85^{\circ} 2 \theta$ range were measured. The volume fraction of the $m$ phase, $\nu_{m}$, can be represented by [29]:

$v_{m}=\frac{1.311 X_{m}}{1+0.311 X_{m}}$

where $X_{m}$ is the integrated intensity ratio expressed by

$X_{m}=\frac{I_{m}(\overline{1} 11)+I_{m}(111)}{I_{m}(\overline{1} 11)+I_{m}(111)+I_{t}(101)}$

where subscripts $m$ and $t$ represent the monoclinic and tetragonal phase, respectively. There should exist three phases, $t, c$ and $m$ phase in APS-TBC, however the $c$ and $t$ phases were not distinguished in this study, therefore both $t$ and $c$ phases were counted as the $t$ phase in this study, which should not affect the study of the formation of the $m$ phase and its effect on the mechanical and electrical properties of TBCs.

The local phases of TBC samples were identified at room temperature using the Renishaw Ramanscope 2000 (Renishaw ${ }^{\mathrm{TM}}$, Gloucestershire, UK) in conjunction with an Olympus BH-2 microscope. During the measurements, a He-Ne laser $(632.8 \mathrm{~nm})$ was focused at a position on the cross section of a TBC and the laser spot size was set at about $3-5 \mu \mathrm{m}$. The measurement range of Raman is from 200 to $800 \mathrm{~cm}^{-1}$ to detect the local phases in TBCs.

The density of the sample was obtained by dividing the weight with the volume of the sample. The TBCs were polished following a standard metallurgical procedure finishing with the finest $0.25 \mu \mathrm{m}$ diamond paste. The microstructures of both the fracture surfaces and polished surfaces of the samples were examined using a scanning electron microscope equipped with an energy dispersed X-ray spectrometer (SEM-EDX, ZEISS EVO60).

\section{Results and discussion}

\subsection{Microstructures}

TBCs are normally used in the temperature range between $1300{ }^{\circ} \mathrm{C}$ and $900{ }^{\circ} \mathrm{C}$ with a temperature gradient across the TBC thickness of around $200 \mu \mathrm{m}$ [11]. Previously sintering of an APS-TBC has been found to occur at $1100{ }^{\circ} \mathrm{C}$ after $114 \mathrm{~h}$ [22]. In this study, $1400{ }^{\circ} \mathrm{C}$ was used to speed up the sintering process. Fig. 1 shows the cross sections of free standing TBCs before and after sintering at $1400{ }^{\circ} \mathrm{C}$ for different times. These images display the existence of inter-splat boundaries as indicated by arrows and pores of more than a few micrometers diameter. There is no significant change of the polished TBC surface due to sintering. However, evidence of sintering can be observed as 'necks' of inters-plat boundaries which were formed after $50 \mathrm{~h}$ sintering are indicated with arrows in Fig. 1-(b)-(d). Fig. 2 gives the 

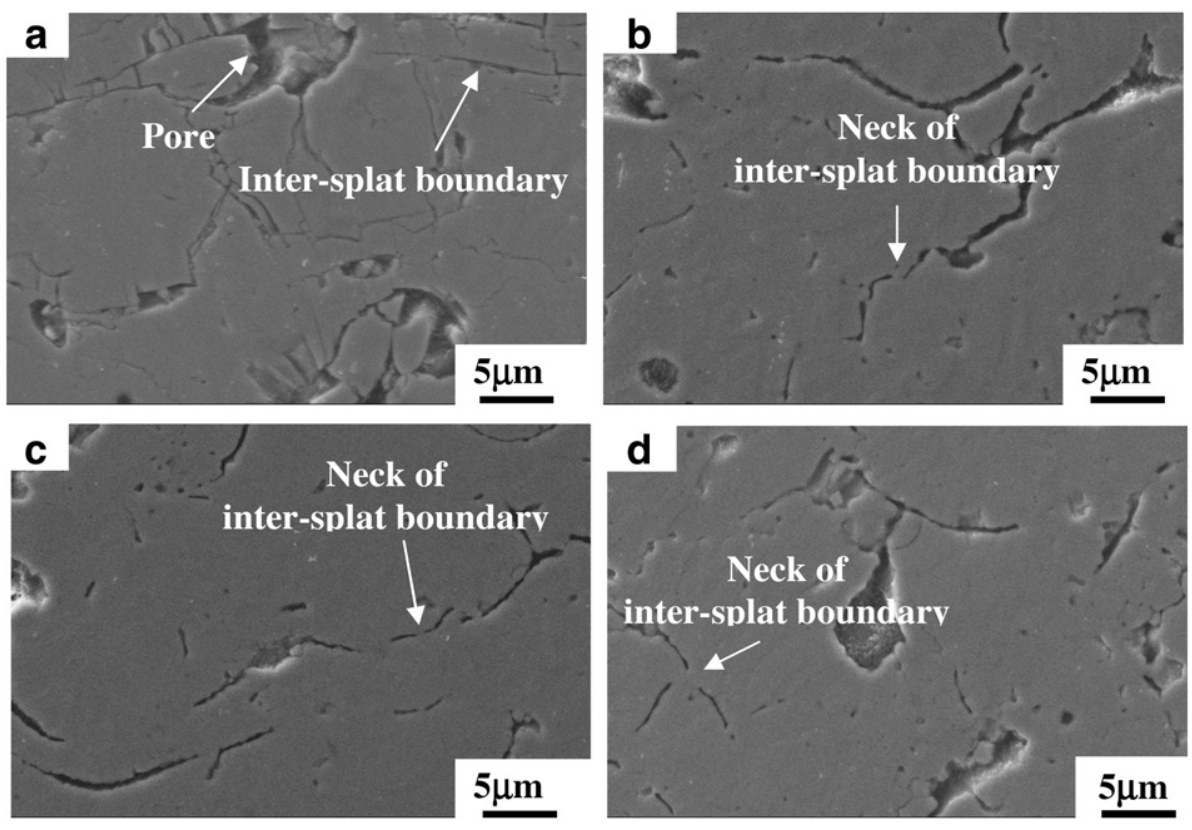

Fig. 1. The cross sections of free standing TBCs of (a) as-sprayed, after (b) $50 \mathrm{~h}$, (c) $100 \mathrm{~h}$, and (d) $200 \mathrm{~h}$ sintering at $1400{ }^{\circ} \mathrm{C}$.

cross sections of free standing TBCs sintered for more than $50 \mathrm{~h}$ in a low magnification. Although a densification should occur and the density of the TBCs should increase with the thermal treatment time due to sintering, large cracks were generated in TBCs after more than $200 \mathrm{~h}$ thermal treatment, as shown by arrows in Fig. 2-(b) and (c). This is due to the $m$ phase formation causing the crack generation and the reduction of the density (Fig. 6 shown later) [30]. Fig. 2-(d) shows typical Raman spectra of the TBCs sintered for $50 \mathrm{~h}$ in a grain and the TBCs sintered for $200 \mathrm{~h}$ at a crack tip, which is the area I in Fig. 2-(a) and the area II in Fig. 2-(b) respectively, in the $200-800 \mathrm{~cm}^{-1}$ range. $t$ and $m$ in Fig. 2-(d) corresponds with peak of the tetragonal and the monoclinic phase, respectively [30]. The peaks corresponding with only $t$ phase can be seen in the spectra of the TBCs sintered for $50 \mathrm{~h}$ in a grain, while the peaks corresponding with $m$ phase also can be seen
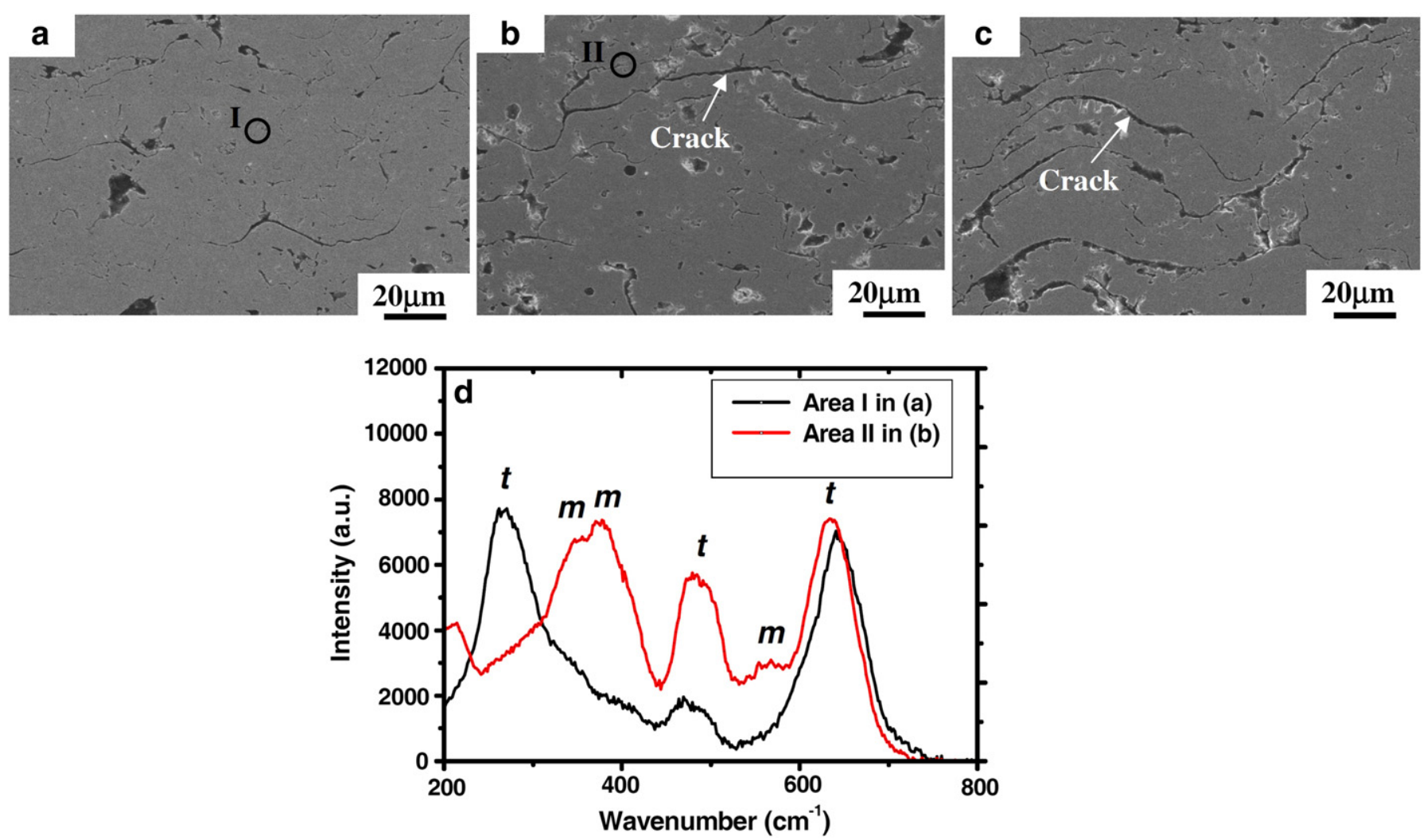

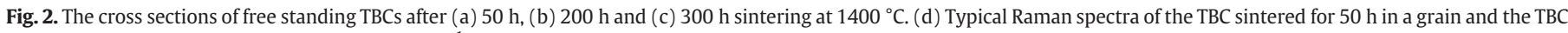

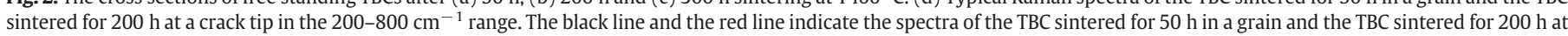
a crack tip, which is the area I and the area II in (a) and (b), respectively. Indices: $m=$ monoclinic, $t=$ tetragonal. 
in the spectra in the TBCs sintered for $200 \mathrm{~h}$ at a crack tip. This implies that the $m$ phase is preferably formed at the crack tips.

Fig. 3 shows the fracture surfaces of the samples shown in Fig. 1. The vertical direction in Fig. 3 is the through thickness direction of the TBCs. Columnar grains were formed from rapid solidification during the thermal spray process and remain even after heat treatment. However, the diameter of the columnar grain increases with the sintering time, which is in agreement with a previous study [31]. The diameter of the columnar grain in the as-sprayed coating is approximately $200 \mathrm{~nm}$, which increased to about $700 \mathrm{~nm}$ after $50 \mathrm{~h}$ sintering, then to more than $1 \mu \mathrm{m}$ after $200 \mathrm{~h}$ sintering.

\subsection{Phase transformation and mechanical properties of TBCS}

Fig. 4 gives typical XRD patterns of the as-sprayed TBC, and the samples sintered for $100 \mathrm{~h}, 200 \mathrm{~h}$ and $300 \mathrm{~h}$, which were used to calculate the volume fraction of the $m$ phase in the TBC. The $t(101)$, $m(\overline{1} 11)$ and $m(111)$ peaks in a range of $2 \theta$ between $27^{\circ}$ and $33^{\circ}$ were used to obtain the $m$ phase volume fraction. Note that vertical axis, which is the intensity of X-rays, is a logarithmic scale to increase the weak $m$ phase peak. The peaks correlated with the $m$ phase increase with sintering time. Based on the intensity of these peaks and Eq. (2), the volume fraction of $m$ phase can be obtained.

Fig. 5 shows the volume fraction of $m$ phase of TBC as a function of sintering time at $1400{ }^{\circ} \mathrm{C}$. The content of $m$ phase is similar until $50 \mathrm{~h}$ sintering, which is approximately $1.0 \%$, and then the phase transformation occurred with the content of $m$ phase increasing to around $35 \%$ after $300 \mathrm{~h}$ sintering. Meanwhile, density measurements were made on these samples. Fig. 6 gives the relationship between the density of the coating and the sintering time. The density rises dramatically with $50 \mathrm{~h}$ sintering due to densification, then reduces with $100 \mathrm{~h}$ sintering, which may be caused by the formation of the $m$ phase. Such a phase transformation is accompanied by a volume expansion and crack generation [30]. The reduction of the density can be recognised from the microstructures as shown in Fig. 2.

Fig. 7 gives the Young's modulus and hardness of the TBC as a function of sintering time. The Young's modulus and hardness rapidly increases after sintering for $50 \mathrm{~h}$, which is due to densification and necking between splats without a phase transformation. After that

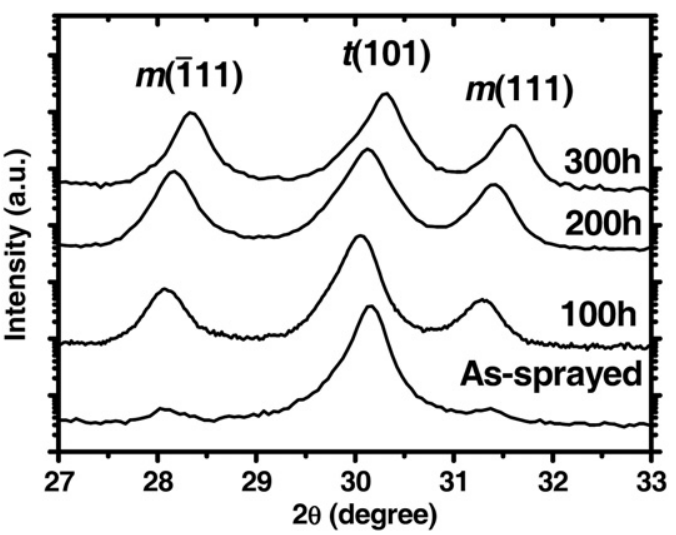

Fig. 4. Typical XRD patterns of the as-sprayed TBC, the sample sintered for $100 \mathrm{~h}, 200 \mathrm{~h}$ and $300 \mathrm{~h}$ in the $27-33^{\circ} 2 \theta$ range, which is used to calculate the $m$ phase content.

these properties are reduced by sintering for $100 \mathrm{~h}$ and then remain similar after further sintering to $300 \mathrm{~h}$. Because the $m$ phase formation occurred rapidly after $100 \mathrm{~h}$ sintering and is accompanied with around 4-5\% volume expansion, a reduction of toughness [32] and formation of new cracks (Fig. 2-(b)-(c)) [30], which may lead to a decrease in the apparent Young's modulus and hardness of TBCs. Therefore, the mechanical properties of TBCs are initially affected by the TBC densification and then by the formation of $m$ phase in the TBC.

It has been reported that a material with a low ratio of hardness to its Young's modulus $(H / E)$ has a high degree of plastic deformation [33], therefore it is important to express the $H / E$ ratio to examine the deformation capability of TBCs. Fig. 8 indicates the relationship between the $m$ phase ratio and the $H / E$ ratio. The $H / E$ ratio is hardly altered until $50 \mathrm{~h}$ sintering but then decreases with the formation of the $m$ phase, implying the formation of the $m$ phase leads to an increase in capability of plastic deformation of TBCs. The relationship between the $m$ phase ratio $\left(\nu_{m}\right)$ and the $H / E$ ratio is linear and the best fit can be expressed by:

$$
v_{m}=1.930-28.28 \frac{H}{E} \text {. }
$$
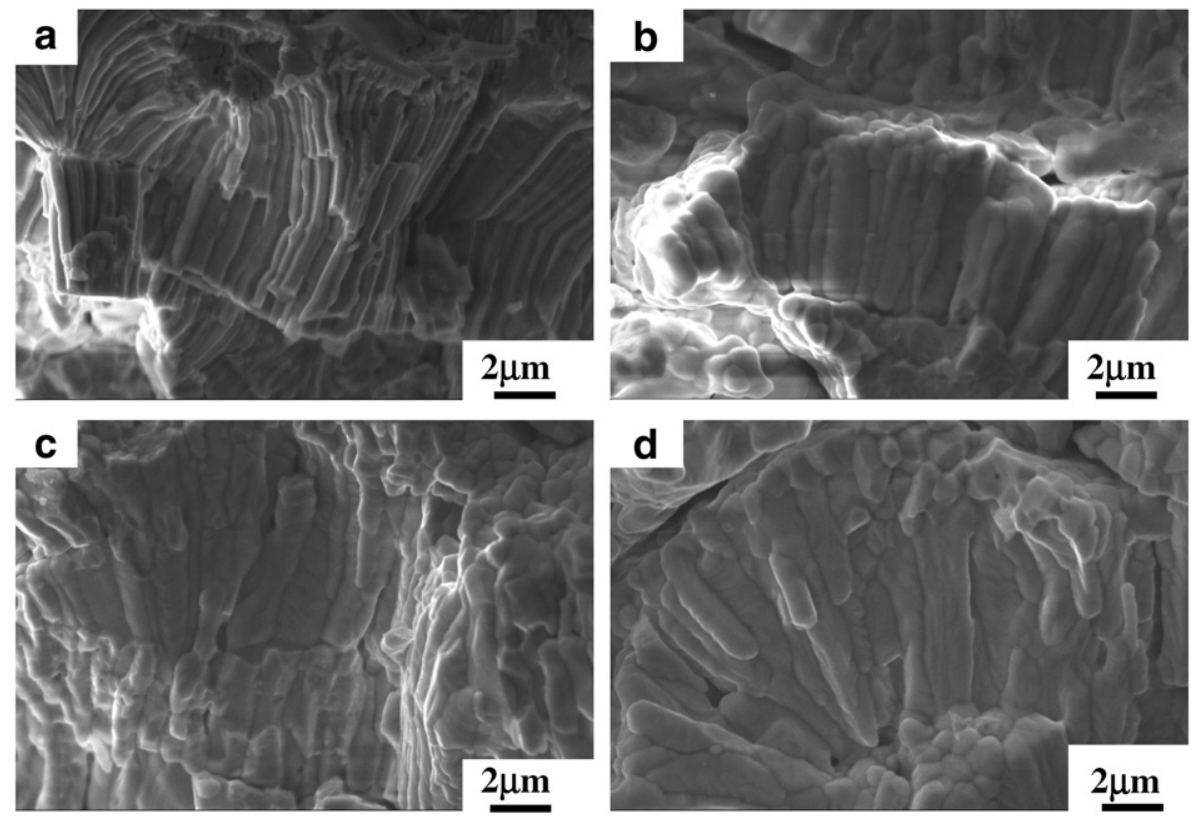

Fig. 3. The fracture surfaces of free standing TBCs of (a) as-sprayed, after (b) $50 \mathrm{~h}$, (c) $100 \mathrm{~h}$, and (d) $200 \mathrm{~h}$ sintering at $1400{ }^{\circ} \mathrm{C}$. 


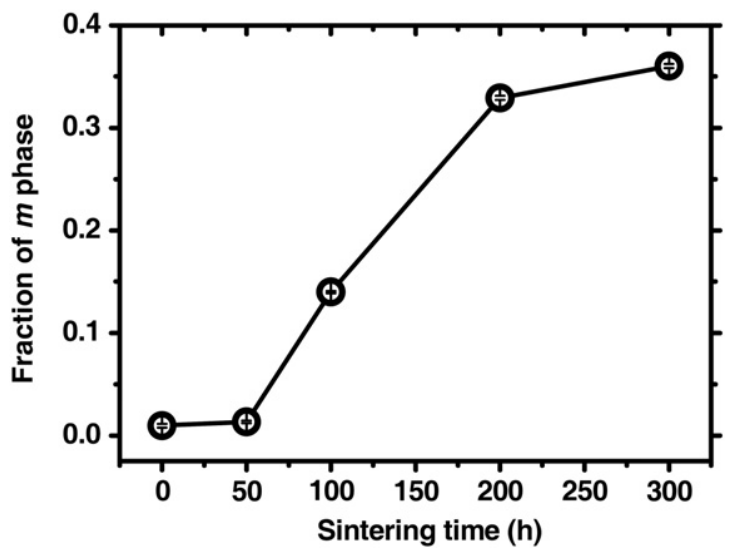

Fig. 5. The volume fraction of monoclinic phase of TBCs, obtained from XRD measurements, as a function of sintering time at $1400{ }^{\circ} \mathrm{C}$. The error bars stand for standard deviations, which are within the marks.

It is known that the $H / E$ ratio can be expressed by [34,35]:

$\frac{H}{E}=a-b \frac{W_{i r}}{W_{t}}$

where $a$ and $b$ are constants, and $W_{i r}$ and $W_{t}$ stand for the irreversible work and total work done by the hardness indenter during the loading process of indentation test, which can be represented as:

$\frac{W_{i r}}{W_{t}}=\frac{W_{t}-W_{u}}{W_{t}}$

where $W_{u}$ indicates the work done by the indenter during the unloading process, as illustrated by Fig. 9. Therefore, assuming the loading curve is identical, the material has a high plastic deformation capability when the slope of the unloading curve, $S$, is high since irreversible work is large, resulting in a low $H / E$ ratio. On the other hand, Young's modulus, E, can be defined by [28]:

$\frac{1}{E_{r}}=\frac{1-v^{2}}{E}+\frac{1-v_{i}^{2}}{E_{i}}$

$E_{r}=\frac{\sqrt{\pi}}{2 \sqrt{A}} S$

where $E$ and $\nu$ are Young's modulus and Poisson's ratio for the samples and $E_{i}$ and $\nu_{i}$ are the same parameters for the indenter, $E_{r}$ is the reduced modulus, which is the effect of a non-rigid indenter on the load-displacement behaviour, $A$ is the projected area of the elastic

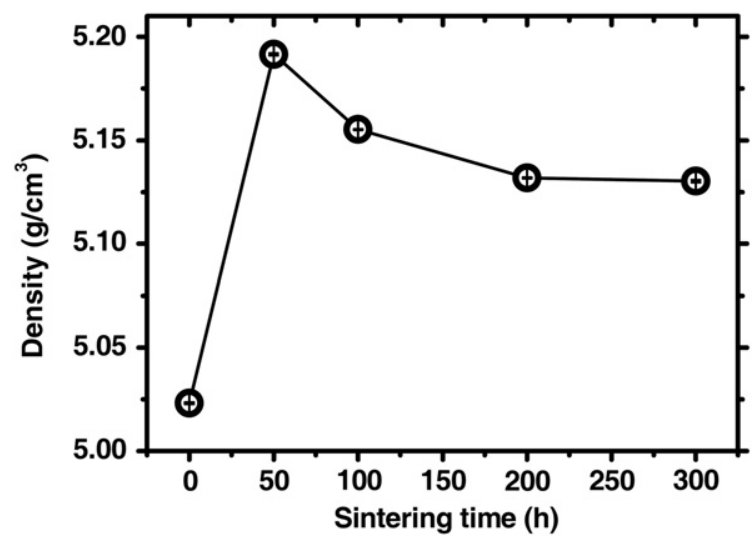

Fig. 6. The density of TBCs as a function of sintering time at $1400{ }^{\circ} \mathrm{C}$. The error bars stand for standard deviations, which are within the marks.

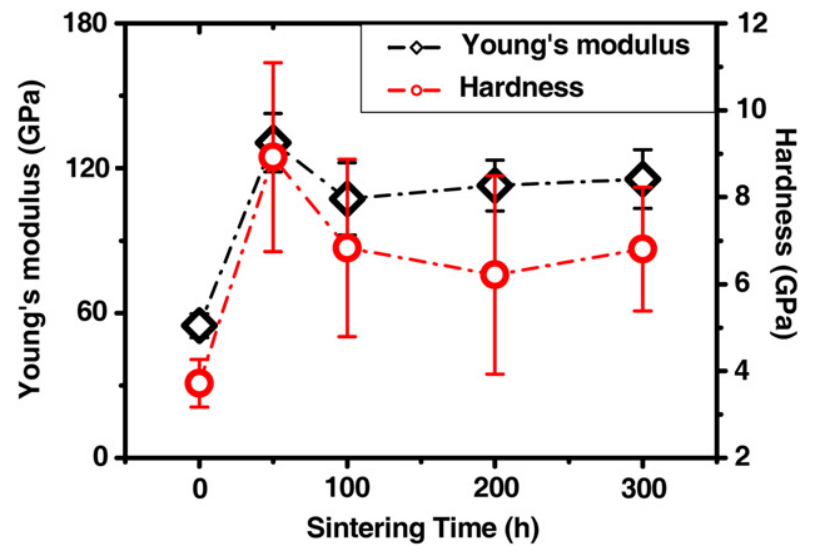

Fig. 7. Young's modulus and hardness of TBCs as a function of sintering time. The black line and the red line indicate Young's modulus and hardness, respectively. The error bars give standard deviations.

contact. From Eq. (7) assuming $A$ is same, the value of $E_{r}$ is large when the slope of the unloading curve, $S$, is high, meaning a high degree of plastic deformation. In this case Young's modulus of the sample, $E$, has a large value from Eq. (6) since $\nu, E_{i}$ and $\nu_{i}$ are fixed. Consequently, the sample having a high Young's modulus should have the trend to give a high plastic deformation capability. It is reported that the Young's modulus of the $m$ phase is larger than that of the $t$ phase [36], therefore the $m$ phase should have a higher plastic deformation capability than the $t$ phase. Also cracks are generated accompanying the $m$ phase formation [30]. When the sample has a high content of pores, transmission of stress is dominated by a small solid area which is much smaller that the macroscopic indentation contact area. In this case, the stress is concentrated at these small solid regions and this leads to plastic and brittle deformation. Therefore a porous material has more micro-fractures than a dense material under the same macroscopic strain [37]. Hence unloading is more difficult since the indenter makes a larger plastic region and smaller elastic region than a fully-dense material, meaning the unloading curve is near a vertical line after the maximum load in the displacement curve and the irreversible work, $W_{i r}$, is larger. Thus, a porous material should have a higher plastic deformation capability than a dense material. As a result, because the Young's modulus of the $m$ phase is larger than that of the $t$ phase and the $m$ phase formation is related to crack generation, the $m$ phase contributes to the plastic deformation capability.

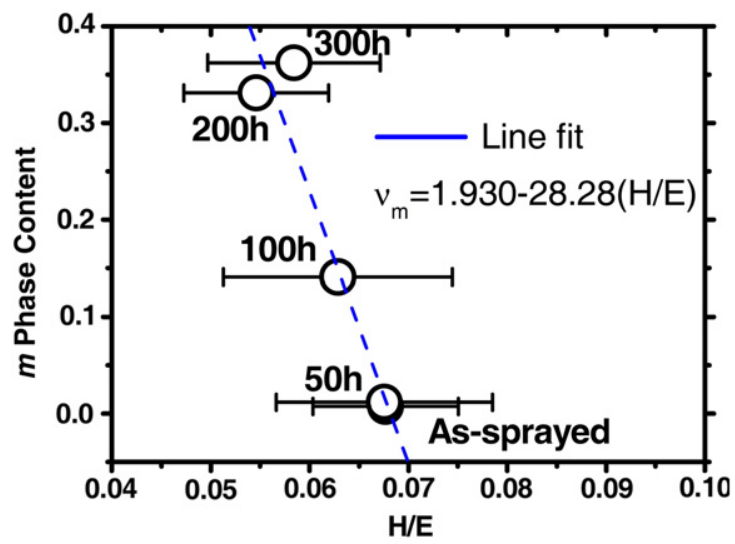

Fig. 8. The relationship between the monoclinic phase content and ratio of measured hardness to the Young's modulus $(H / E)$. The error bars give standard deviations. The blue line indicates the best fit relationship between the monoclinic phase content and the $H / E$ ratio. The time inserted in the graph is sintering time. 


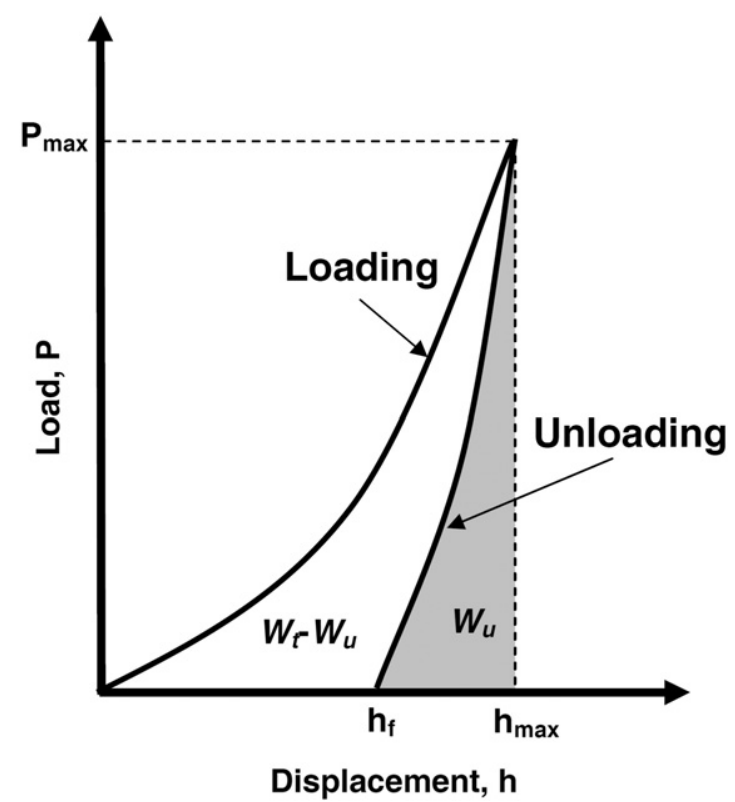

Fig. 9. Schematic diagram of a load-displacement curve during indentation. The total work done by the indenter $\left(W_{t}\right)$ is defined as the area beneath the loading curve, and the reversible work $\left(W_{u}\right)$ is the area beneath the unloading curve.

\subsection{Impedance measurements of $T B C S$}

The electrical properties of materials have been measured by impedance spectroscopy. There are different ways of expressions of impedance data, in which Nyquist and Bode plots, are most frequently used. The Nyquist plot represents the real part, $Z^{\prime}$, versus the imaginary part, $Z^{\prime \prime}$, with the total impedance as $Z(\omega)=Z^{\prime}+j Z^{\prime \prime}$, where $\omega$ is the angular frequency and $j=\sqrt{-1}$. The Bode plot displays the impedance, $Z(\omega)$, the imaginary part , $Z^{\prime \prime}$, the phase angle, $\theta=\tan ^{-1}\left(\frac{Z^{\prime \prime}}{Z^{\prime}}\right)$, or modulus of the impedance as a function of the frequency, $f=\frac{\omega}{2 \pi}$. For a single resistor-capacitor (R-C) circuit, the Nyquist plot is normally shown with a single semi-circle while the Bode plot of phase angle or the imaginary part is shown with a peak at a certain frequency.

In many cases, the Nyquist plot is not a full semi-circle but a depressed one with the circle centre below the horizontal axis. In this case, the use of a capacitor in the $\mathrm{R}-\mathrm{C}$ circuit cannot represent the electrical behaviour of a material, which normally has some chemical inhomogeneity and geometrical non-uniformity. Therefore, a constant phase element (CPE) should be used to model this deviation instead of an ideal capacitance element in the equivalent circuit. The impedance of a CPE, $Z_{C P E}$, is given by [21]:

$Z_{C P E}=\frac{1}{A(j \omega)^{n}}$

where $A$ is a parameter independent of frequency. When the exponential factor $n=1$, the CPE functions as an ideal capacitor and $A$ is equal to the capacitance, $C$. When $n=0$, the CPE acts as a pure resistor. Normally, $n$ is between 0 and 1 , meaning a non-ideal capacitance response. In this case, $A$ cannot be used as the capacitance of the system. Here, we adopt an equivalent capacitance, $C$, which may be acquired by [38]:

$C=R^{\frac{1-n}{n}} A^{\frac{1}{n}}$

where $R$ is the resistance.

Fig. 10 expresses the typical impedance Nyquist plots of free standing TBCs before and after sintering for different times. The impedance response was obviously affected by the heat treatment. Basically two clearly separated arcs are produced for each sample in the Nyquist plots, except only less clearly separated arcs are displayed for the as-sprayed coating, which is due to overlapping between two semi-circles or arcs. A previous study has shown a similar phenomenon, i.e. for an as-sprayed APS coating the two semi-circles (arcs) in the Nyquist plot and two peaks in the Bode plot are less clear than that for a sintered coating $[39,40]$. The two semi-circles (arcs) for the as-sprayed TBC reduced with sintering for $50 \mathrm{~h}$. However, with sintering from $100 \mathrm{~h}$ the diameter of the low frequency semi-circle in

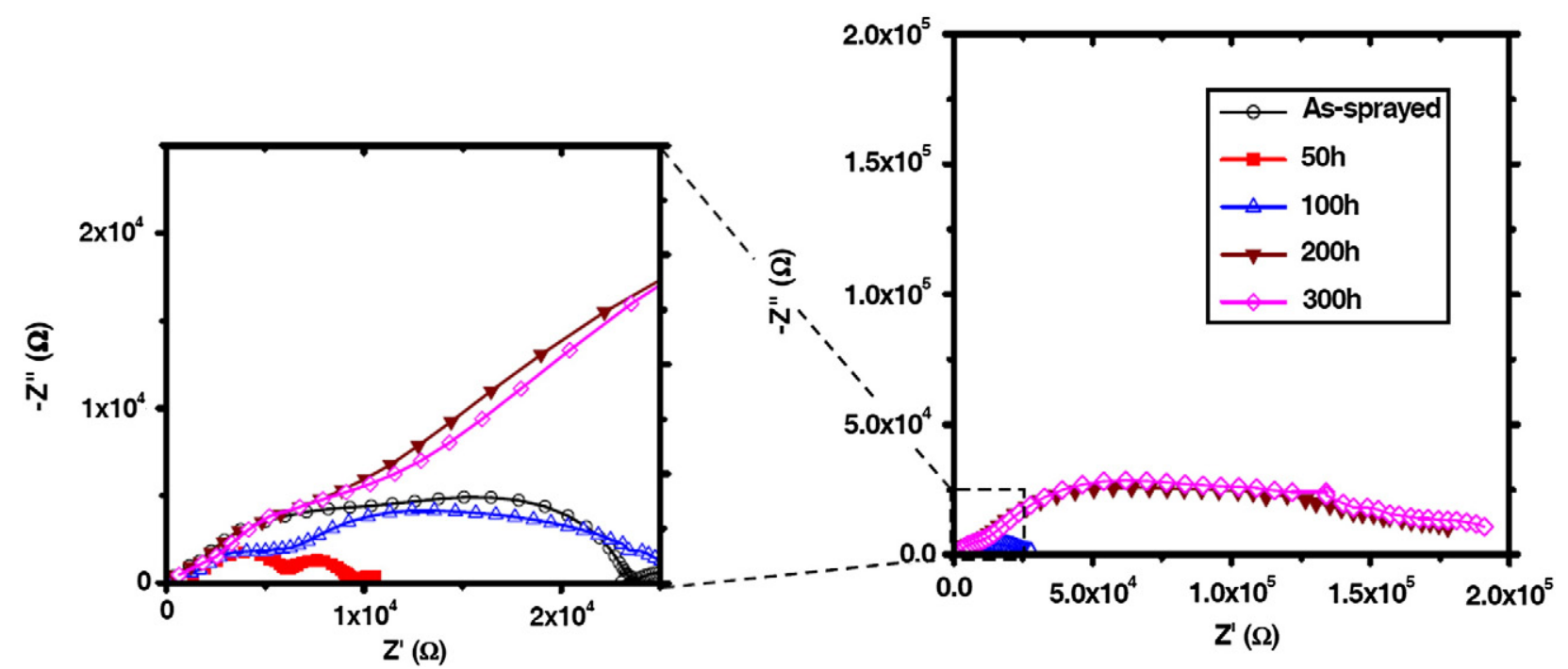

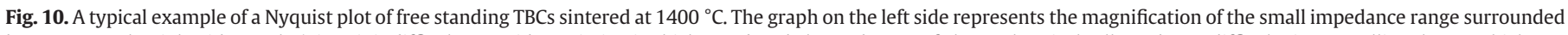

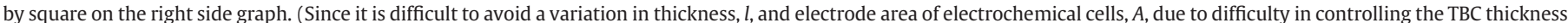

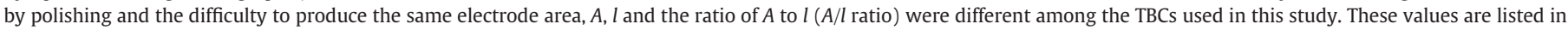

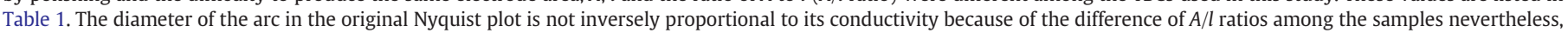
therefore, Fig. 10 is drawn with a calibration based on the $A / l$ ratio, meaning the diameter of the arc in Fig. 10 is inversely proportional to its conductivity.) 
particular increased considerably, which coincides with the formation of the $m$ phase as identified by XRD. The semi-circles at the high and low frequencies in the Nyquist plots normally relates to grains and grain boundaries in polycrystalline ceramics [38]. However, since the conductivity of the $m$ phase is comparable to that of the grain boundaries [21,41], the semi-circles corresponding to grain boundaries and the $m$ phase overlap in Nyquist plots. Also, it is reported that since the $m$ phase is formed along grain boundaries, the $m$ phase formation affects the semi-circle in the low frequency side [23]. Therefore, we treat the large semi-circle at a low frequency as a grain boundary plus monoclinic $m$ phase $(g b+m)$ peak.

Fig. 11 illustrates the Bode plots ( $Z^{\prime \prime}$ vs frequency) of the TBCs before and after sintering, which gives a specific peak corresponding to the $m$ phase [39]. Two peaks in Fig. 11 can be obviously seen at approximately $10^{6} \mathrm{~Hz}$ and $10^{4} \mathrm{~Hz}$ for the as-sprayed TBC and the TBC sintered for $50 \mathrm{~h}$, and a peak at low frequency appears between $10^{4} \mathrm{~Hz}$ and $10^{3} \mathrm{~Hz}$ for TBCs sintered for more than $100 \mathrm{~h}$. This peak should be associated with the formation of the $m$ phase since the $m$ phase is more electrically resistive than YSZ grains and grain boundaries [39]. In addition, XRD analysis has shown the formation of the $m$ phase after sintering for more than $100 \mathrm{~h}$. Previous studies have also indentified that the peak at around $10^{6} \mathrm{~Hz}$ and $10^{4} \mathrm{~Hz}$ correspond to grains $(g)$ and grain boundaries $(g b)$ respectively [41], and the peak between $10^{4} \mathrm{~Hz}$ and $10^{3} \mathrm{~Hz}$ is related to the $m$ phase [39]. These plots again suggest an overlap between the $m$ phase peak and $g b$ peak. It should be noted here that the peak at $10^{-1} \mathrm{~Hz}$ is associated with the electrode effect [39].

It has been reported that the $\sigma_{g}$ (grain conductivity) of a fullydense material was not changed regardless of the sintering condition [17] whereas the $\sigma_{g}$ and $\sigma_{g b}$ of a porous material changed depending on the density and the sintering temperature $[18,19]$, suggesting that the effect of pores overlaps with that of both $g$ and $g b$ unless pores are filled with conductive material [42]. Similarly, cracks or voids in TBCs are not conductive, which should affect both semicircles in their impedance spectra. For a TBC sintered for $50 \mathrm{~h}$, the densification of a TBC with a reduction of voids and cracks in the TBC leads to a reduction of impedance, i.e. a reduction of the semi-circles. Further sintering for more than $100 \mathrm{~h}$ led to the $m$ phase formation and a volume increase, when the effect of sintering on impedance is less significant than that of the $m$ phase formation. Since it is difficult to separate the effect of grain boundaries and the $m$ phase and it is equally difficult to identify the effect of voids/cracks in the impedance

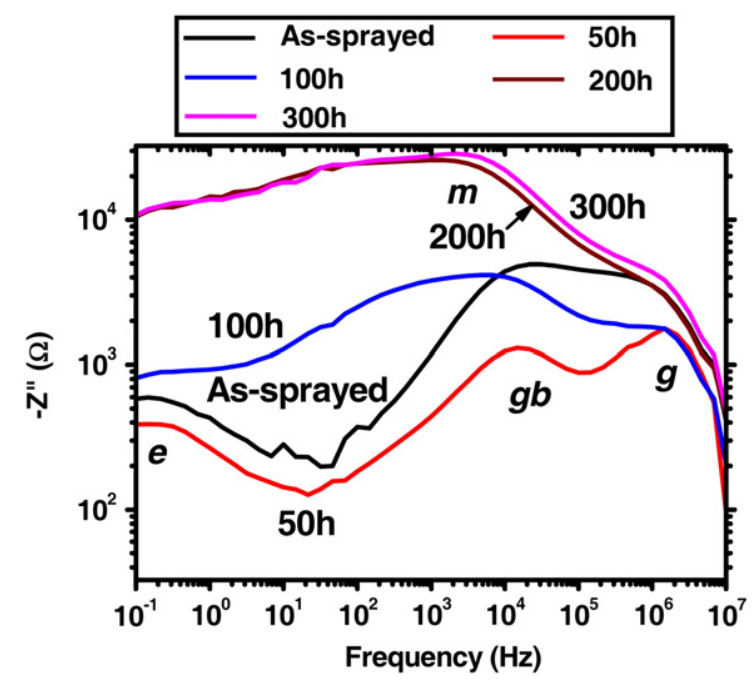

Fig. 11. Typical examples of Bode plots (imaginary impedance $\left(Z^{\prime \prime}\right)$ versus frequency $(f))$ of the free standing TBCs. Indices: $g=$ grain, $g b=$ grain boundary, $m=$ monoclinic phase, $e=$ electrode. spectra, we have to simplify the equivalent circuit representing the TBC with two elements as shown in Fig. 12-(a).

In this case, we assume one element represents YSZ grains in TBCS with a contribution of voids or cracks. The other element represents $g b$ and the $m$ phase, plus an effect from voids and cracks. To simplify the explanation, we relate the first element (the high frequency circle) to the $g$ knowing it contains an effect of cracks/voids, and the second element to the $g b$ plus $m$ phase (the low frequency semicircle) knowing it also contains an effect of crack/voids.

Fig. 12-(b) depicts the conductivity of $g$ and $g b$ plus the $m$ phase as a function of sintering time at $1400{ }^{\circ} \mathrm{C}$, which is given by:

$\sigma_{g}=\frac{1}{\rho_{g}} \quad \rho_{g}=R_{g} \frac{A}{l}$

$\sigma_{g b+m}=\frac{1}{\rho_{g b+m}} \quad \rho_{g b+m}=R_{g b+m} \frac{C_{g b+m}}{C_{g}} \frac{A}{l}$

where $\rho$ is the resistivity, $\sigma$ is the conductivity, $R$ is the diameter of the semi-circle, $C$ is the capacitance and subscripts $g$ and $g b+m$ mean grains and grain boundaries plus the monoclinic phase, respectively. $l$ stands for thickness of TBCs and $A$ is the electrode area [43]. The capacitance can be obtained according to:

$C_{g}=\frac{1}{2 \pi R_{g} f_{g}} \quad C_{g b+m}=\frac{1}{2 \pi R_{g b+m} f_{g b+m}}$

where $f$ represents the relaxation frequency.

Table 1 gives the value of $R$ and $f$ for all samples to calculate their conductivities.

The conductivity of $g b+m\left(\sigma_{g b+m}\right)$ is approximately two orders of magnitude lower than that of $g\left(\sigma_{g}\right)$, which is in accordance with previous reports $[41,44]$. $\sigma_{g}$ dramatically rises after sintering for $50 \mathrm{~h}$ and then remain similar to sintering for $100 \mathrm{~h}$, which indicates a significant reduction of voids/cracks in TBCs. For sintering from $100 \mathrm{~h}$
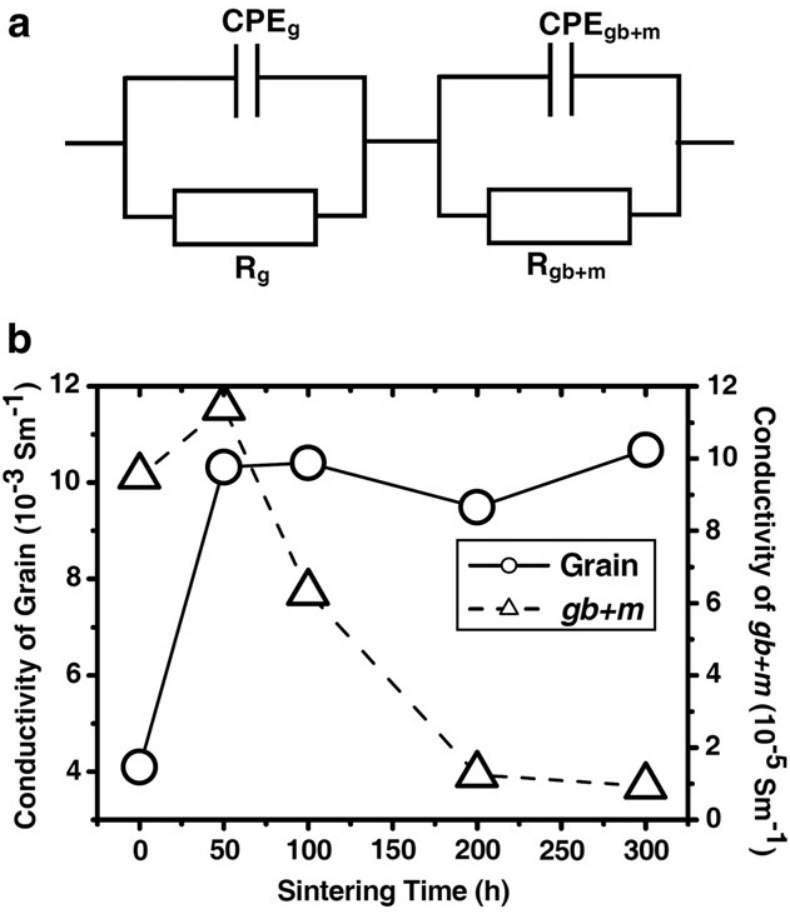

Fig. 12. (a) Equivalent circuit model for a TBC system with $R_{g}$ representing grains and $\mathrm{R}_{\mathrm{gb}+\mathrm{m}}$ representing grain boundaries and the monoclinic phase. (b) The conductivity of grains and grain boundaries plus the monoclinic phase of free standing TBCs as a function of sintering time. The solid line and the broken line indicate the conductivity of grains and grain boundaries plus monoclinic phase, respectively. 
Table 1

The values of electrode area, A, sample thickness, $l$, resistance, $R$, and relaxation frequency, $f$.

\begin{tabular}{llllll}
\hline & As-spray & $50 \mathrm{~h}$ & $100 \mathrm{~h}$ & $200 \mathrm{~h}$ & $300 \mathrm{~h}$ \\
\hline $\begin{array}{l}\text { Electrode area }\left(\mathrm{A} / \mathrm{m}^{2}\right) \\
\text { Sample thickness }(l / \mathrm{m})\end{array}$ & $1.83 \mathrm{e}-5$ & $2.93 \mathrm{e}-5$ & $2.25 \mathrm{e}-5$ & $1.53 \mathrm{e}-5$ & $2.02 \mathrm{e}-5$ \\
$\mathrm{~A} / \mathrm{l}$ ratio $(\mathrm{m})$ & $2.29 \mathrm{e}-2$ & $4.00 \mathrm{e}-4$ & $7.00 \mathrm{e}-4$ & $7.60 \mathrm{e} 4$ & $5.50 \mathrm{e}-4$ \\
$\begin{array}{c}\text { Resistance of grain }\left(R_{\mathrm{g}} / \Omega\right) \\
\text { Resistance of } g b+m\end{array}$ & $1.07 \mathrm{e} 4$ & $4.25 \mathrm{e} 3$ & $4.21 \mathrm{e}-2$ & $2.01 \mathrm{e}-2$ & $3.73 \mathrm{e}-2$ \\
$\quad\left(R_{g b+m} / \Omega\right)$ & $1.11 \mathrm{e} 4$ & $3.78 \mathrm{e} 3$ & $1.74 \mathrm{e} 4$ & $4.62 \mathrm{e} 3$ & $4.10 \mathrm{e} 3$ \\
$\begin{array}{c}\text { Relaxation frequency } \\
\text { of grain }(f g / \mathrm{Hz})\end{array}$ & $9.78 \mathrm{e} 5$ & $1.48 \mathrm{e} 6$ & $9.01 \mathrm{e} 5$ & $9.09 \mathrm{e} 5$ & $2.31 \mathrm{e} 5$ \\
$\begin{array}{c}\text { Relaxation frequency } \\
g b+m\left(f_{g b+m} / \mathrm{Hz}\right)\end{array}$ & $2.27 \mathrm{e} 4$ & $1.63 \mathrm{e} 4$ & $5.44 \mathrm{e} 3$ & $1.20 \mathrm{e} 3$ & $2.02 \mathrm{e} 3$ \\
\hline
\end{tabular}

$g b=$ grain boundaries, $m=$ monoclinic phase.

to $300 \mathrm{~h}$, there is a slight variation, indicating a much smaller change in the contents of voids and cracks in TBCs. $\sigma_{g b+m}$ also increases moderately with sintering for $50 \mathrm{~h}$, which also suggests a reduction in voids and cracks, although to a much less extent inside grains than at grain boundaries. For sintering from $100 \mathrm{~h}$ to $300 \mathrm{~h}, \sigma_{g b+m}$ shows a steady and considerable decrease, which should be related to the formation of the $m$ phase.

Although new cracks are generated accompanying the formation of the $m$ phase [30], these new cracks appeared not to affect $\sigma_{g}$ since $\sigma_{g}$ did not change considerably even after the formation of a significant amount of the $m$ phase. This may be because these cracks formed due to the formation of the $m$ phase are created near to the $m$ phase [30]. Thus, the reduction of the $\sigma_{g b+m}$ is due to the formation of the $m$ phase and formation of new cracks.

The blocking coefficient $\left(\alpha_{R}\right)$ was defined in a previous study to examine the effect of an insulating element in a conductive matrix [45]:

$\alpha_{R}=\frac{R_{g b}}{R_{g}+R_{g b}}$

Nevertheless, since the effect of $g b$ and the $m$ phase overlaps in the Nyquist plots in this study as discussed previously, Eq. (14) is used as the blocking coefficient:

$\alpha_{R}=\frac{R_{g b+m}}{R_{g}+R_{g b+m}}$

Here we apply this equation to examine the blocking effect of $g b+$ $m$ phase and calculate the blocking effect in TBCs using the data given in Table 1 . To show the relation between the blocking factor of $g b+m$ $\left(\alpha_{R}\right)$ and the volume fraction of the $m$ phase $\left(\nu_{m}\right)$, Fig. 13 shows a plot of $\alpha_{R}$ vs $\nu_{m}$

In a single phase polycrystalline material, $\alpha_{R}$ normally decreases with grain growth because of a reduction of $g b$ area [46], therefore $\alpha_{R}$ decreases with sintering for $50 \mathrm{~h}$. Thereafter $\alpha_{R}$ increases with an increase in the $m$ phase content. The apparent effect of the $m$ phase formation on the blocking coefficient suggests that 1) the effect of $m$ overlaps with that of $g b$ in the impedance due to their comparable conductivity [21,41], 2) the $m$ phase may nucleate at $g b$ [23], with new crack formation along the $m$ phase [30]. Therefore measurements of the blocking coefficient can be used to determine the formation of the $m$ phase.

On the other hand, although Young's modulus and hardness are not sensitive to the $m$ phase formation since these mechanical properties of the samples sintered for more than $100 \mathrm{~h}$ did not change as shown in Fig. 7 despite the formation of the $m$ phase, $\sigma_{g b+m}$, the $H / E$ ratio, which indicates the deformation capability of TBCs, may be more sensitive to the $m$ phase formation than Young's modulus and hardness. Fig. 14 shows the conductivity of the grain boundaries plus the monoclinic phase $\left(\sigma_{g b+m}\right)$ as a function of the ratio of the

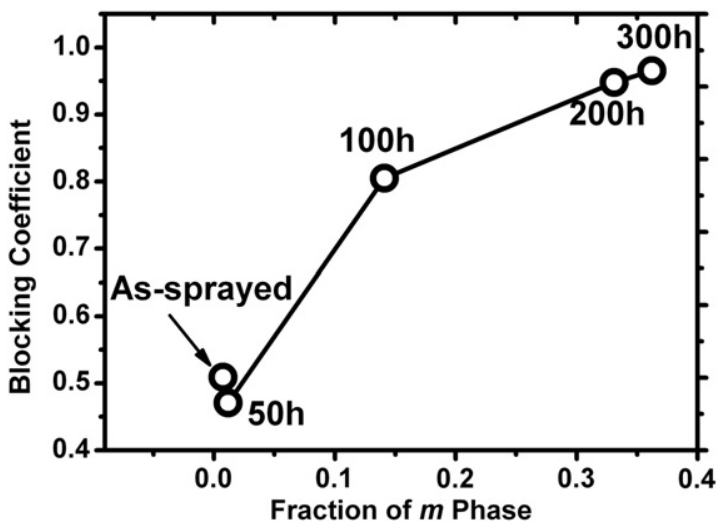

Fig. 13. The relationship between the blocking coefficient and the volume fraction of the monoclinic phase of free standing TBCs. The time inserted in the graph is the sintering time.

measured hardness to the Young's modulus $(H / E)$. Although there is a large error bar in these measurements, an attempt has been made to fit this relationship with a linear equation as follows:

$\sigma_{g b+m}=-4.625 \times 10^{-4}+8.416 \times 10^{-3} \frac{H}{E}(\mathrm{~S} / \mathrm{m})$.

Both Fig. 14 and Eq. (15) suggest that there is a relationship between the mechanical properties and measured electrical properties. However, the data from the as-sprayed TBC is not included because this relationship only examines the effect of the $m$ phase formation, not the effect of the sintering on the deformation ability of TBCs.

It should be noted that such a relation cannot be applied to extreme situations, i.e. when the $H / E$ ratio is less 0.055 , which means the $m$ phase content is higher than $40 \%$, since then $\sigma_{g b+m}$ becomes negative, which is not reasonable. However, for normal TBCs, the $m$ phase content should be much less than $40 \%$ for gas turbines used at temperatures lower than $1400{ }^{\circ} \mathrm{C}$ [11], this relationship may be applicable to APS TBCs in general.

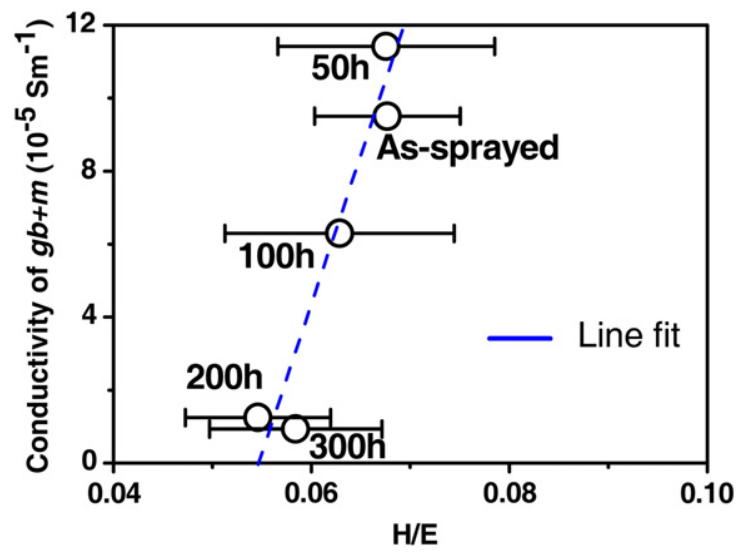

Fig. 14. The conductivity of and grain boundaries plus the monoclinic phase as a function of the ratio of measured hardness to the Young's modulus $(H / E)$. The error bars stand for standard deviation. The blue line indicates the best fit relationship between conductivity of $g b+m$ and the $H / E$ ratio except for the as-sprayed coating. The time inserted in the graph is the sintering time. Indices: $g b=$ grain boundaries, $m=$ monoclinic phase. $\sigma_{\mathrm{gb}}+\mathrm{m}=-4.625 \times 10^{-4}+8.416 \times 10^{-3}(H / E)$. 


\section{Conclusions}

TBCs comprising $\mathrm{ZrO}_{2}-8$ wt.\% $\mathrm{Y}_{2} \mathrm{O}_{3}$ were sintered at $1400{ }^{\circ} \mathrm{C}$ for up to $300 \mathrm{~h}$. The impedance of the as-sprayed and the sintered coatings were measured at $400{ }^{\circ} \mathrm{C}$ and the Young's modulus and hardness of these samples were obtained with an indentation technique. In addition, the $m$ phase content was measured using XRD. Based on the above measurements, the following conclusions have been obtained.

i) The $m$ phase was not generated until sintering for $50 \mathrm{~h}$ and in this interval the Young's modulus, hardness and the conductivities increased because of the disappearance of pores, which can be recognised from an increment of density.

ii) After the TBCs were sintered for more than $100 \mathrm{~h}$, the $m$ phase was formed and the density was reduced, consequently the Young's modulus and hardness decrease. Also, the formation of the $m$ phase increases the plastic deformation capability and decreases the electrical conductivity of TBCs.

iii) Although the conductivity of the $m$ phase is close to that of $g b$ of YSZ, the formation of the $m$ phase can be detected based on measurements of Bode plots (imaginary impedance $\left(Z^{\prime \prime}\right)$ versus frequency $(f)$ ) or the blocking coefficient.

iv) The relationship between $H / E$ and the fraction of the $m$ phase in TBCs suggests that the formation of the $m$ phase leads to an increase in deformation capability of TBCs.

\section{References}

[1] U. Schulz, C. Leyens, K. Fritscher, M. Peters, B. Saruhan-Brings, O. Lavigne, J. Dorvaux, M. Poulain, R. Mevrel, M. Caliez, Aero. Sci. Tech. 7 (2003) 73.

[2] R.A. Miller, Surf. Coat. Tech. 30 (1987) 1.

[3] J.T. DeMasi-Marcin, D.K. Gupta, Surf. Coat. Tech. 68-69 (1994) 1.

[4] N.P. Padture, M. Gell, E.H. Jordan, Science 296 (2002) 280.

[5] D.L. Ruckle, Thin Solid Films 73 (1980) 455.

[6] I.R. Gibson, J.T.S. Irvine, J. Am. Ceram. Soc. 84 (2001) 615.

[7] R.W. Trice, Y.J. Su, J.R. Mawdsley, K.T. Faber, A.R. De Arellano Lopez, H. Wang, W.D. Porter, J. Mater. Sci. 37 (2002) 2359.
[8] V. Lughi, D.R. Clarke, J. Am. Ceram. Soc. 88 (2005) 2552.

[9] J. Ilavsky, J.K. Stalick, Surf. Coat. Tech. 127 (2000) 120.

[10] T. Hilpert, E. Ivers-Tiffée, Solid State Ionics 175 (2004) 471.

[11] R.A. Miller, J. Therm, Spray Tech. 6 (1997) 35.

[12] A. Bennett, F.C. Toriz, A.B. Thakker, Surf. Coat. Tech. 32 (1987) 359.

[13] P.A. Langjahr, R. Oberacker, M.J. Hoffmann, J. Am. Ceram. Soc. 84 (2001) 1301

[14] D. Renusch, M. Schutze, Surf. Coat. Tech. 202 (2007) 740.

[15] G. Newaz, X. Chen, Surf. Coat. Tech. 190 (2005) 7.

[16] X. Peng, D.R. Clarke, J. Am. Ceram. Soc. 83 (2000) 1165.

[17] D.Z. de Florio, R. Muccillo, Solid State Ionics 123 (1999) 301.

[18] I.R. Gibson, G.P. Dransfield, J.T.S. Irvine, J. Mater. Sci. 33 (1998) 4297.

[19] X.J. Chen, K.A. Khor, S.H. Chan, L.G. Yu, Mater. Sci. Eng. A335 (2002) 246.

[20] S.P.S. Badwal, Solid State Ionics 76 (1995) 67.

[21] N. Bonanos, B.C.H. Steele, E.P. Butler, W.B. Johnson, W.L. Worrell, D.D. Macdonald M.C.H. McKubre, in: J.R. Macdonald (Ed.), Applications of Impedance Spectroscopy, University of North Carolina Press, Impedance Spectroscopy, 1987.

[22] J.A. Thompson, T.W. Clyne, Acta Mater. 49 (2001) 1565.

[23] C. Bowen, S. Ramesh, C. Gill, S. Lawson, J. Mater. Sci. 33 (1998) 5103.

[24] N.Q. Wu, K. Ogawa, M. Chyu, X. Mao, Thin Solid Films 457 (2004) 301.

[25] K. Ogawa, D. Mincov, T. Shoji, M. Sato, H. Hashimoto, NDT \& E Int. 32 (1999) 177.

[26] F. Tang, J.M. Schoenung, Scripta Mater. 54 (2006) 1587.

[27] A. Selçuk, A. Atkinson, J. Euro. Ceram. Soc. 17 (1997) 1523.

[28] W.C. Oliver, G.M. Pharr, J. Mater. Res. 7 (1992) 1564.

[29] H. Toraya, M. Yoshimura, S. Somiya, J. Am. Ceram. Soc. 67 (1984) C119.

[30] D.R. Clarke, F. Adar, J. Am. Ceram. Soc. 65 (1982) 284.

[31] J. Luo, S. Adak, R. Stevens, J. Mater. Sci. 33 (1998) 5301.

[32] P.M. Kelly, L.R.F. Rose, Prog. Mater. Sci. 47 (2002) 463.

[33] X. Zhao, P. Xiao, Thin Solid Films 515 (2007) 8393.

[34] J. Malzbender, G. de With, Surf. Coat. Tech. 135 (2000) 60.

[35] T. Cheng, C. Cheng, Appl. Phy. Lett. 73 (1998) 614.

[36] E. Yeugo, Y. Lorgouilloux, M. Huger, C.P. Gault, J. Mater. Sci. 41 (2006) 7663-7666.

[37] L. He, O.C. Standard, T.T.Y. Huang, B.A. Latella, M.V. Swain, Acta Biomater. 4 (2008) 577.

[38] S.H. Song, P. Xiao, L.Q. Weng, J. Euro. Ceram. Soc. 25 (2005) 1167.

[39] P.S. Anderson, X. Wang, P. Xiao, J. Am. Ceram. Soc. 88 (2005) 324

[40] X. Wang, J. Mei, P. Xiao, J. Euro. Ceram. Soc. 21 (2001) 855.

[41] L. Deng, Y. Xiong, P. Xiao, Surf. Coat. Tech. 201 (2007) 7755.

[42] J. Gomez-Garcia, A. Rico, M.A. Garrido-Maneiro, C.J. Munez, P. Poza, V. Utrilla, Surf. Coat. Tech. 204 (2009) 812

[43] X. Guo, W. Sigle, J. Fleig, J. Maier, Solid State Ionics 154-155 (2002) 555.

[44] X. Guo, Z. Zhang, Acta Mater. 51 (2003) 2539.

[45] L. Dessemond, R. Muccillo, M. Henault, M. Kleiz, Appl. Phys. A57 (1993) 57.

[46] A.P. Santos, R.Z. Domingues, M. Kleitz, J. Euro. Ceram. Soc. 18 (1998) 1571. 